\title{
Satisfaction of Basic Needs and its Repercussion in the Course of Development
}

\author{
Daniela Bergesch D'Incao Marronet \\ Claudio Simon Hutz' \\ ${ }^{1}$ Universidade Federal do Rio Grande do Sul, Porto Alegre, RS
}

\begin{abstract}
Self-determination Theory (SDT) has an organismic and dialectical framework for the study of personality growth and development. From SDT's perspective, individuals are prone to develop towards an active and integrative way. Therefore, there are three basic needs that must be satisfied: autonomy, relatedness and competence. Through the association between personal characteristics and the satisfaction of needs development and integration will be allowed. This paper will discuss SDT precepts and how the satisfaction of these needs reverberates throughout development.

Key words: self-determination; motivation; human development
\end{abstract}

Satisfação de Necessidades Básicas e Sua Repercussão no Curso do Desenvolvimento

\begin{abstract}
Resumo
A Teoria da Autodeterminação (TAD) é uma teoria organísmica e dialética que considera os indivíduos como ativos no processo de desenvolvimento, com potencial para o crescimento e integração. Para tanto é fundamental que três necessidades básicas sejam satisfeitas: autonomia, relação e competência. É através do interjogo das características pessoais e dos nutrientes dados pelo meio que irá permitir ou não o bom desenvolvimento e integração. Este trabalho propõe-se a discutir os preceitos da TAD e a forma como a satisfação dessas necessidades repercute ao longo do desenvolvimento.

Palavras-chave: autodeterminação; motivação; desenvolvimento humano
\end{abstract}

Satisfacción de Necesidades Básicas y Su Repercusión en el Curso del Desarrollo

\section{Resumen}

La Teoría de la Autodeterminación (TAD) es una teoría organicista y dialéctica que considera como individuos activos en el proceso de desarrollo, con un potencial de crecimiento e integración. Por lo tanto, es esencial que se cumplan tres necesidades básicas: autonomía, relación y competencia. Es a través de la interacción de las características personales y los datos de los nutrientes a través que va a permitir o no permitir el desarrollo y la integración con éxito. Este trabajo tiene como objetivo discutir los preceptos del TAD y como la forma de satisfacer esas necesidades reverbera a lo largo del desarrollo.

Palabras clave: la autodeterminación; motivación; el desarrollo humano

\section{Introduction}

Among the many ways of understanding human development, the Self-Determination Theory (SDT) considers that human psychological development is dynamically adaptive, with a tendency towards a cohesive functioning of the self ${ }^{1}$ (Ryan \& Deci, 2000a, Ryan \& Deci, 2017). The self is the central axis for healthy functioning: it is integrative, albeit fluid, and processes a large number of important functional meanings (Ryan \& Deci, 2017). SDT examines how cultural, biological and social conditions can increase or inhibit psychological growth, engagement, and well-being, overall or in some specific area or challenge (Ryan \& Deci, 2017).

TAD conceptualizes the self as being the psychological organization that integrates and structure whose narratives, new functions, values, preferences and regulations are integrated (Ryan \& Deci, 2017).
It is a theory that approaches the motivation and the personality named after an organismic methateory ${ }^{2}$ (Deci \& Ryan, 1985). It considers the importance of personal resources for personality development and self-regulation of behavior, provided that the environment supports such development (Ryan \& Deci, 2000b). In this sense, when the environment provides these resources, it leads to a better use of them, ensuring that basic psychological needs are met, which are: competence, relatedness and autonomy (Deci \& Ryan, 2000). The need for competence involves the feeling of being able and effective in the social environment, relatedness refers to feeling connected and involved with others and, finally, autonomy refers to volitional functioning (Ryan \& Deci, 2000b; Ryan \& Deci, 2017). These are characterized as innate psychological

2 It is a theory that sees individuals as active in growth, capable of continually adapting and integrating new experiences into a cohesive sense of self (Deci \& Ryan, 1985). 
nutrients for growth, integrity and well-being (Deci \& Ryan, 2000).

Thus, this provision is necessary throughout the life cycle. Studies have found evidence that in childhood, the more parents or caregivers use control, the greater the damage in the feelings of autonomy and competence of the children. On the contrary, when they stimulate and support autonomy, children feel more competent and autonomous (Deci \& Ryan, 1985). Another study pointed to evidence that when the parents are of the controlling type, the children tend to have worse school performance, whereas children of parents who support their autonomy tend to have better school performance $(\mathrm{Ng}$, Kenney-Benson, \& Pomerantz, 2004).

In adults who have experienced relationships based on conditional positive regard ${ }^{3}$ throughout development, there are indications that this practice involves affective cost such as, for example, oscillations of selfesteem and resentment toward parents (Assor, Roth, \& Deci, 2004). Furthermore, in affective and friendly relationships, non-fulfillment of the need for autonomy may lead to lower quality relationships (Kanat-Maymon, Roth, Assor, \& Raizer, 2016).

Studies with elderly living in Care homes for Seniors emphasize the importance of an environment that provides the three basic needs (Custers, Weterhof, Kuin, Gerritsen, \& Riksen-Walraven, 2012; Ferrand, Martinent, \& Durmaz, 2014). In addition, when relatedness and autonomy needs are met, there is a positive association with indicators of well-being (Ferrand et al., 2014).

The studies cited above exemplify some of the different ways in which it is necessary that the needs be met from birth to old age. Therefore, because we understand that contributions of this theory are consistent, this study aims to discuss the precepts of SDT, illustrating some of its central concepts, such as: basic needs, regulation of behavior, and motivation. Furthermore, by means of a brief review of studies in the field, it explores the importance of satisfaction of basic needs in different domains and the repercussion through the life cycle.

\section{Self-Determination Theory}

The SDT was created by Richard M. Ryan and Edward L. Deci in the 1980's and it addresses the

\footnotetext{
Conditional positive regard refers to the belief that consideration of a particular person depends on meeting one's expectations (Assor, Roth, \& Deci, 2004)
}

themes of motivation and personality (Deci \& Ryan, 2008). It began with studies on the effects of the environment in intrinsic motivation and it is currently a broad motivational theory of personality (Deci \& Ryan, 2008). This was developed with the use of traditional empirical methodology and it was regarded as an organismic metatheory, which emphasizes the use of internal resources for personality development and self-regulation of behavior (Ryan, 1995; Deci \& Ryan, 2000; Ryan, Kuhl, \& Deci, 1997).

It considers human beings as active organisms, which act according to the internal and external environment. It is, therefore, a dialectical theory, since it understands that the potential of development exists, nevertheless the environment plays a fundamental role, it can serve both as support and to inhibit the growth of individuals (Ryan \& Deci, 2017). The inherent tendency of growth and the psychological needs will function as a basis for motivation, integration of personality and the necessary conditions for a good development (Deci \& Ryan, 2000). Vulnerability situations in turn, involve passivity and the formation of fragmented structures that cause rigid psychological functioning (Ryan \& Deci, 2002).

From the basic needs to be met for a full development, autonomy is considered the central construct in the SDT, and it refers to the desire or volition with respect to a certain goal and the need to feel in charge of one's own actions (Ryan \& Deci, 2017). It can be seen as a phenomenological or functional issue: From the phenomenological viewpoint, it provides the extent to which individuals feel that their behaviors are free and in tune with their desire, not feeling any kind of control or coercion by forces outside the self (Ryan \& Deci, 2017). From the functional point of view, there is an autonomous behavior when people act according to their interest and desires using their own resources, interest and abilities (Ryan \& Deci, 2017).

Autonomous individuals also need, in a significant way, important and interdependent relationships of relevant groups (Ryan \& Deci, 2017). The opposite of autonomy is heteronomy, in which case the individual can accept the determination of others, as long as he endorses this decision as if it were his own (Van Petegem, Beyers, Vansteenkiste, \& Soenens, 2012).

Competence refers to the feeling of effectiveness in one's interactions with the social environment, experiencing opportunities to exercise and express one's abilities (Deci \& Ryan, 2002). For this need to be met, it is essential that the challenges faced be proportional 
to one's capacities and, consequently providing maintenance and continuous development of capabilities through the activity (Deci \& Ryan, 2002). It is a sense of trust and effectiveness (Deci \& Ryan, 2002).

Relatedness as a need, in turn, is the feeling of connection with others, of caring and being cared for. It is a sense of belonging to a group and the community in general (Ryan \& Deci, 2002). Even when one appreciates solitude, a well-built relational foundation provides a sense of security and functions as the basis for intrinsic motivation (Deci \& Ryan, 2000).

The feeling of being related, belonging to a group, and the feeling of being competent, serve as facilitators of the tendency to the natural internalization of the values and regulations present in the social groups in which they are inserted (Ryan \& Deci, 2017). The support for the relation and competence promote the internalization of a regulation or value, but they are not enough to support the integration (Ryan \& Deci, 2017). In this sense, the freedom to process and endorse transmitted values and regulations, that is, a sense of autonomy, is fundamental (Deci \& Ryan, 1985; Deci \& Ryan, 2000).

The adequate provision of needs sets the tone for the type of motivation behind the behaviors adopted. For example, the need for autonomy is ensured through the provision of it, the need for competence is met when, for example, parents are able to provide an environment of good structure, challenges consistent with children's ability, and the establishment of clear and concise limits. In turn, the need for relatedness is guaranteed through parental care and involvement (Ryan, Deci, Grolnick, \& La Guardia, 2006). Behaviors that involve greater autonomy, more attuned to the individual's desires and values, tend to lead to positive outcomes with feelings of interest and satisfaction (Ryan et al., 2006).

Depending on the level at which needs are met, a greater or lesser degree of motivation for action will be possible (Ryan \& Deci, 2017). There is a distinction between two broad classes of motivation for behaviors, the self-determined and the controlled. The first involves the experience of a sense of choice (selfdetermination), while the latter involves subjection and subordination to psychic forces or other individuals (Deci, Eghrari, Patrick, \& Leone, 1994a; Deci \& Ryan, 1985). Given the constant exchange between the individual and the environment, they way in which the satisfaction of the needs is carried out ensures or not the maintenance of a proper functioning. Just as it is necessary to supply biological demands, satisfaction at the psychological level promotes mental health and awareness of goals and values (Ryan \& Deci, 2002).

Behaviors adopted by individuals are regulated by different types of motivation, denoting greater or lesser personality integration. The integration process is complex and involves two issues in the socialization of individuals: the first would be to accept and regulate the motivation to perform tasks that in themselves would not be intrinsically motivated (e.g.: to perform household tasks), but which allow for a greater feeling of effectiveness in relation to the social group in which they are inserted (Ryan \& Deci, 2017). The second question concerns the integration and regulation of emotions, implying how each person will manage impulses and find ways of expressing and mastering them. In addition, it involves experiences of autonomy, competence and relatedness (Ryan \& Deci, 2017). The degree to which the individual is able to integrate cultural demands, values, and regulations reflects the type of engagement with the demands (Deci \& Ryan, 2000).

Motivation serves as the motor or vital force for activity and development of internal structures. Despite being treated as an individual generator, there are several factors that motivate people to adopt certain behaviors and actions, and there are several consequences (Ryan \& Deci, 2000a).

\section{Motivation}

In this perspective, the motivation is explained through a motivational continuum that goes from amotivation (lack of motivation), to extrinsic motivation, and to intrinsic motivation. It is important to point out that the type of motivation manifests itself differently, depending on the internal and external environments of each individual. There is no order, each specific situation will reflect a type of motivation (Deci \& Ryan, 2000; Ryan \& Deci, 2000b; Ryan \& Deci, 2002). For example, some behaviors may have started by external regulation, and during exposure they may awaken properties that are felt to be intrinsically motivated, generating a change in the type of regulation (Ryan \& Deci, 2000a).

In amotivation the individual does not show any intention to adopt any type of behavior in the face of a stimulus, there is lack of motivation, passivity and inactivity (Deci \& Ryan, 2000). There is a lack of sense of efficacy and control over a given situation, configuring the inability to regulate a type of behavior (Deci \& Ryan, 2000). 
Regulation by extrinsic motivation manifests itself in different ways. It may occur due to some kind of external contingency, such as a prize or reward, or to avoid some kind of punishment or retaliation (Deci \& Ryan, 2000). An example may be a worker whose only objective is to receive the payment at the end of the month, taking no pleasure in performing the activity (Deci \& Ryan, 2000). When the motivation is given by internalized regulation, the subject feels the motivation as his own, however, external control is at stake, where the individual acts in order to avoid feelings of guilt, shame and desire for a guarantee of recognition (Deci \& Ryan, 2000; Ryan \& Deci, 2000a, Ryan \& Connell, 1989; Ryan \& Deci, 2002). An example of this kind of regulation is when the person adopts certain behavior as a way of not hurting others' expectations.

Also classified as extrinsic motivation, regulation by identification is more self-determined, involving the acceptance of elements that are important for the individual (Deci \& Ryan, 2000). In this case, what the subject identifies with is taken as their own, endorsed by them and there is an important level of autonomy involved (Deci \& Ryan, 2000). We can think of the example of a student who admires the involvement and commitment of his or her teacher and therefore adopts a similar attitude by identification.

Integrated regulation, in turn, promotes the basis for a more autonomous form of extrinsically motivated behavior. It occurs when the identification was evaluated as in line with the values, goals and needs of the individual. Although this type of regulation is considered part of the individual, it is classified as external because the motivation still occurs for certain purposes, rather than for the simple pleasure or interest inherent in the action (Deci \& Ryan, 2000).

Intrinsic motivation is the most autonomous regulation, it is based on innate needs for competence and self-determination (Deci \& Ryan, 1985; Ryan \& Deci, 2006). It serves as a propeller for a wide range of psychological behaviors and processes in which the reward is the experience of autonomy and competence (Deci \& Ryan, 1985; Ryan \& Deci, 2006). It is the inherent tendency to search for novelties and challenges, exerting the capacities of learning and exploration (Ryan, 1995; Ryan \& Deci, 2000).

For intrinsic motivation to operate self-determination is paramount (Ryan \& Deci, 2000a). In this sense the experience of freedom is a condition and must be present at the beginning of each behavior intrinsically motivated (Ryan \& Deci, 2000a). The
SDT seeks to understand the conditions that extract and sustain or subjugate and diminish this innate propensity (Ryan \& Deci, 2000a).

Like intrinsic motivation, internalization is considered by SDT to be a natural active process in which people continually adopt practices and regulations of their social group, transforming them into self-regulations and enabling them to be performed later in an independent and volitional way (Deci \& Ryan, 2000; Ryan \& Deci, 2017). When the process of internalization flows satisfactorily, there is the ability of individuals to identify themselves with important aspects of the regulation of the environment in which they live, assimilating these into an integrated sense of self (Deci \& Ryan, 2000)

The internalization and integration of extrinsic motivation as well as intrinsic motivation are the basis for autonomous and self-determined behavior (Deci \& Ryan, 2000; Deci \& Ryan, 2000b; Ryan \& Deci, 2006). However, it is important to consider that fully internalized extrinsic motivation will never become an intrinsic motivation, even if it is in tune with the individual's values and desires, as it yet possesses an instrumental character (Deci \& Ryan, 2000). This is due to the fact that certain behavior was adopted by the importance of reaching a certain goal or outcome, even if perceived as volitional and valued by the self (Ryan \& Deci, 2000a).

Another aspect of the processes of integration and internalization of values and behaviors culturally endorsed by individuals is that they are facilitators of the satisfaction of basic needs (Ryan \& Deci, 2000b). When needs are met, there is the capacity for autonomy, relatedness and competence, regardless of the culture in which they are inserted (Ryan \& Deci, 2000b). Therefore, these psychological needs are considered universal, since they represent innate requirements rather than acquired reasons (Deci \& Ryan, 2008; Ryan $\&$ Deci, 2000b).

The claim to universality is often debated, as in the case of autonomy, for example. In some cases, the difference in the manifestation of intrinsic motivation and importance attributed to autonomy in individualist and collectivist societies is questioned (Iyengar \& Lepper, 1999). However, there are studies that corroborate the hypothesis of universality. An example of this is a study that found evidence that regardless of culture, there seems to be a positive relationship between internalized or autonomous regulation, cultural practices, and wellbeing (Chirkov, Kim, Ryan, \& Kaplan, 2003). Another study that shows evidence of universality compared 
samples of North American and Bulgarian workers and found that the constructs are similar in both cultures (Deci et al., 2001).

In addition to studies comparing basic needs in different cultures, countless investigations explore the repercussion of satisfying these needs throughout the life cycle. Among these, stands out the importance of intrinsic motivation for autonomous behavior, as well as an environment that facilitates the development of competencies.

\section{Satisfaction of Basic Needs throughout the Life Cycle}

The studies described in this study were retrieved from two sources: scientific journals and books published with an emphasis on SDT. The articles were retrieved from "Portal Periódicos Capes" and "PsycINFO" using the descriptors "basic needs" and "self-determination theory" present in the abstract between the years 2000 and 2017. At the Capes database there were 130 articles, from which four were selected. In the "PsycINFO" database 82 articles were found and seven were selected, two of which were repeated. The remaining articles were retrieved from references of articles and books used via Google Scholar. In addition, 6 books on the subject of SDT were consulted. We chose studies whose reports addressed the subject of satisfying the basic needs of autonomy, competence and relatedness in different areas and periods of human development.

The literature on the early stages of development places particular emphasis on the development of autonomy and relational quality between parents and children. There is evidence that during the early school years, when there is parental support for the autonomy of the children, there is greater consideration regarding the child's point of view, appreciation and encouragement for the child to think and solve their own problems, minimizing the use of parental control (Grolnick \& Ryan, 1989). Children who receive support for autonomy, demonstrate higher levels of autonomous self-regulation, less control, greater perception of competence, as well as better school performance (Grolnick, Ryan, \& Deci, 1991; Lee, Yu, \& Choi, 2012). Factors that hinder the provision of autonomy were identified both externally, as parental stress, and as particular aspects of the child, for example, difficult temperament (Grolnick \& Apostoleris, 2002).

The issue of autonomy draws special attention during adolescence, as individuals gradually acquire greater decision-making power over various aspects of life. Several authors point out the importance of the relationship with parents for a healthy development. In a study with individuals in early adolescence, it was found an association between emotional and behavioral problems (e.g. depression and aggression) and parents perceived as restrictive and controlling. On the contrary, when they are perceived as welcoming and empathic, a lower relation with behavioral problems was evidenced (Finkenauer, Engels, \& Baumeister, 2005).

In an analysis of relationship patterns between adolescents and their mothers, it was observed that in the group with the strongest separation between mothers and children, there were higher levels of conflict, and lower levels of intimacy and perception of admiration (Albert, Trommsdorff, \& Sabatier, 2011). Moreover, at this stage parental involvement and support for autonomy are predictors of better school performance (Wong, 2008).

The type of motivation proves to be an important factor to be considered in school performance. In a study that assessed combinations between intrinsic and extrinsic motivation in students, academic performance correlated positively with intrinsic motivation, and negatively with extrinsic (Hayenga \& Corpus, 2010). This result corroborated findings from earlier studies that indicated positive and reciprocal relationship between intrinsic motivation and school performance (Corpus, McClintic-Gilbert, \& Hayenga, 2009).

In a study that investigated adolescents' motivation in the classes of physical education it was found that when the students perceived the environment as a provider of autonomy it was a positive predictor of fun and negative predictor of boredom. (Karagiannidis, Barkoukis, Gourgoulis, Kosta, \& Antoniou, 2015). In another research with physical activity practitioners, it stood out the role of the satisfaction of basic needs as a mediator in the relation between perceived support of autonomy and psychological well-being, indicating that when needs are met, there is an increase in well-being (Moutão, Alves, Monteiro, \& Cid, 2015).

Teachers also play an important role in motivating their students. Autonomous motivation for teaching promotes autonomous motivation for learning by increasing the student's experience with the teacher who provides the necessary support for autonomy (Roth, Assor, Kanat-Maymon, \& Kaplan, 2007). In addition, it was pointed out the positive association between autonomous motivation for work and job satisfaction (Roth et al., 2007). On the other hand, there was a negative association between autonomous motivation with feelings of exhaustion at work (Roth et al., 2007). 
In the academic environment the SDT instrumentalizes interventions on student motivation for learning. The development of tools helps teachers to maximize the level of intrinsic motivation for learning (Fernandes \& Vasconcelos-Raposo, 2005).

In a sample of university students, a survey on autonomy and its relationship with adjustment indicated that more self-confident individuals suffered less from depression, got good grades, and demonstrated positive attitudes towards college (Lamborn \& Groh, 2009). This fact is supported by previous findings that showed that more autonomous and confident behavior was associated with creative learning, engagement (Roth et al., 2007) and greater energy and vitality (Ryan \& Frederick, 1997)

The relationship between satisfaction of basic needs and subjective well-being was investigated, with satisfaction of each of the three needs contributing to the positive prediction of life satisfaction and vitality. This same study also identified that when needs were frustrated, they were associated with depressed affection (Nishimura \& Takashi, 2016). One research investigated the association between satisfaction of needs, autonomous motivation and objective well-being in multiple domains, resulting in a strong relationship between satisfaction of basic needs and motivation and well being (Milyavskaya \& Koestner, 2011).

One of the contexts in which the difference in family functioning and the provision of needs may be evident is comparing clinical and non-clinical samples. A study was carried out comparing three groups of adolescents: non-clinical, depressed and those with externalizing problems. The results point to a loss in terms of the family relationship of individuals with externalizing pathologies, which may indicate family environments with few conditions for the provision of basic needs (Pavlidis \& McCauley, 2001). With regard to patients with first episode of schizophrenia, they were found to experience lower satisfaction of basic needs when compared to individuals without psychotic episode (Breitborde, Kleinlein, \& Srihari, 2012)

The consequences of meeting the basic needs are often more prominent in the period of childhood and adolescence, however they manifest themselves throughout the life cycle in different ways. In a study with adult couples, it was obtained that the autonomous motivation to stay in the relationship, based on intrinsic reasons, was predictive of greater satisfaction after misunderstandings. As a consequence, there was a lower level of defensiveness, revealing that when there is an autonomous investment in the relationship, there is a more accurate understanding of the context in which the disagreements occurred, leading to greater satisfaction with the relationship in general (Knee, Lonsbary, Canevello, \& Patrick, 2005).

Regarding the satisfaction of the needs and intrinsic motivation in the elderly, Meurer, Benedetti and Mazo (2012) conducted a research on the motivational factors in elderly people who practiced physical exercises in a social program. They found that elderly people who had been practicing physical activity for at least a year demonstrated an increase in motivation for exercise, which can be understood as an increase in the perception of competence and the need to perform, since the exercises were performed in a social environment (Meurer, Benedetti, \& Mazo, 2012).

Satisfying basic needs is essential throughout the life cycle. It may leave deeper marks in the period of childhood and adolescence, but they are not steady; they are updated throughout the life cycle, implying different types of motivation for different types of behaviors and activities.

\section{Final Considerations}

SDT stands as a consistent theory in the field of personality and motivation. Although recent, studies have corroborated the importance of satisfying basic needs throughout development and the significant role of motivation in the most varied contexts.

Important results have been obtained in relation to the school and academic environment, offering a new vision, especially regarding the autonomy construct. This new perspective seeks to remove from the term autonomy the separation between parents and children, highlighting the importance of the need for a relationship for a healthy development. Besides these, other moments of the life cycle are contemplated, demonstrating that throughout life individuals are changing and adapting to new means and contexts.

Although this article is not a systematic review, it can be observed that the great majority of studies are of North American and European origin, which may end up limiting the applicability in other contexts, such as in Brazil. There are relatively few national research publications that assess motivation and satisfaction of needs, validating or constructing new evaluation tools.

An example of this is that in a search for scientific articles in the Capes Database, conducted in July 30, 2018, using the descriptors "self-determination" and 
"basic needs" a total of 178 articles were obtained, and 58 were excluded for being from other areas of knowledge (e.g., political sciences and sociology), 19 were excluded for being repeated, generating a final total of 39 articles. Of these, 14 were Brazilian, with most studies being in the area of physical education (6) and only three in psychology.

We also performed a search on the "Scielo" database on the same date using the same descriptors. We obtained a total of 22 articles, of which only 15 were from the desired area (covering the self-determination theory and basic needs), and only 10 were Brazilian studies. Among these, five were in the area of Psychology and three in the area of Physical Education. Therefore, even if SDT proposes universal concepts and obtains good results in relation to this, it is known that there are peculiarities of each culture, so it is important to conduct more studies at the national level, verifying the adequacy of this theory to the Brazilian context.

In addition, understanding behaviors through the type of motivation and conditions necessary to support basic needs (autonomous functioning, confidence and relatedness) equips professionals from a wide range of areas to work on skills and abilities. Thus they can create intervention strategies that allow and stimulate individuals to develop their potential for personal growth and development.

\section{References}

Albert, I., Trommsdorff, G., \& Sabatier, C. (2011). Patterns of relationship regulation: German and French adolescents' perceptions with regard to their mothers. Family Science, 2(1), 58-67. https:// doi.org/10.1080/19424620.2011.604573

Assor, A., Roth, G., \& Deci, E. L. (2004). The Emotional Costs of Parents' Conditional Regard: A Self-Determination Theory Analysis. Journal of Personality, 72(1), 47-88. https://doi. org/10.1111/j.0022-3506.2004.00256.x

Breitborde, N. J. K., Kleinlein, P., \& Srihari, V. H. (2012). Self-determination and first-episode psychosis: Associations withsymptomatology,social and vocational functioning, and quality of life. Schizophrenia Research, 137, 132-136. https://doi. org/doi: 10.1016/j.schres.2012.02.026

Chirkov, V., Kim, Y., Ryan, R. M., \& Kaplan, U. (2003). Differentiating Autonomy From Individualism and Independence: A Self-Determination
Theory Perspective on Internalization of Cultural Orientations and Well-Being. Journal of Personality and Social Psychology, 84(1), 97-110. https://doi. org/10.1037/0022-3514.84.1.97

Corpus, J. H., McClintic-Gilbert, M. S., \& Hayenga, A. O. (2009). Within-year changes in children's intrinsic and extrinsic motivational orientations: Contextual predictors and academic outcomes. Contemporary Educational Psychology, 34(2), 154 166. https://doi.org/https://doi.org/10.1016/j. cedpsych.2009.01.001

Custers, A. F. J., Weterhof, G. J., Kuin, Y., Gerritsen, D. L., \& Riksen-Walraven, J. M. (2012). Relatedness, autonomy, and competence in the caring relationship: The perspective of nursing home residents. Journal of Aging Studies, 26, 319-326. https://doi. org/doi:10.1016/j.jaging.2012.02.005

Deci, E. L., Eghrari, H., Patrick, B. C., \& Leone, D. R. (1994). Facilitating internalization: the self-determination theory perspective. Journal of Personality, 62(1), 119-142. https://doi. org/10.1111/j.1467-6494.1994.tb00797.x

Deci, E. L., \& Ryan, R. M. (1985). Intrinsic motivation and self-determination in human behavior. New York: Plenum.

Deci, E. L., \& Ryan, R. M. (2000). The "What" and "Why" of Goal Pursuits: Human Needs and the Self-Determination of Behavior. Psychological Inquiry, 11(4), 227-268. https://doi.org/https://doi. org/10.1207/S15327965PLI1104_01

Deci, E. L., \& Ryan, R. M. (2002). Handbook of Selfdetermination Research. University Rochester Press.

Deci, E. L., \& Ryan, R. M. (2008). Self-Determination Theory: A Macrotheory of Human Motivation, Development, and Health. Canadian Psychology, 49(3), 182-185. https://doi.org/10.1037/a0012801

Deci, E. L., Ryan, R. M., Gagne, M., Leone, D. R., Usunov, J., \& Kornazheva, B. P. (2001). Need Satisfaction, Motivation, and Well-Being in the Work Organizations of a Former Eastern Bloc Country: A Cross-Cultural Study of SelfDetermination. Personality and Social Psychology Bulletin, 27(8), 930-942. https://doi.org/https:// doi.org/10.1177/0146167201278002

Fernandes, H. M., \& Vasconcelos-Raposo, J. (2005). Continuum de auto-determinação: validade para 
sua aplicação no contexto esportivo. Estudos de Psicologia, 10(3), 385-395. https://doi.org/http:// dx.doi.org/10.1590/S1413-294X2005000300007

Ferrand, C., Martinent, G., \& Durmaz, N. (2014). Psychological need satisfaction and well-being in adults aged 80 years and older living in residential homes: Using a self-determination theory perspective. Journal of Aging Studies, 30, 104-111. https://doi.org/10.1016/j.jaging.2014.04.004

Finkenauer, C., Engels, R., \& Baumeister, R. (2005). Parenting behaviour and adolescent behavioural and emotional problems: The role of self-control. International Journal of Behavioral Development, 29(1), 58-69. https://doi. org/10.1080/01650250444000333

Grolnick, W. S., \& Apostoleris, N. H. (2002). What make parents controlling? In Handbook of selfdetermination research (p. 161-181). Rochester: The University of Rochester Press.

Grolnick, W. S., \& Ryan, R. M. (1989). Parent styles associated with children's self-regulation and competence in school. Journal of Educational Psychology, 81(2), 143-154. https://doi.org/https://doi. org/10.1037/0022-0663.81.2.143

Grolnick, W. S., Ryan, R. M., \& Deci, E. L. (1991). Inner resources for school achievement: Motivational mediators of children's perceptions of their parents. Journal of Educational Psychology, 83(4), 508-517. https://doi.org/https://doi. org/10.1037/0022-0663.83.4.508

Hayenga, A. O., \& Corpus, J. H. (2010). Profiles of intrinsic and extrinsic motivations: A person-centered approach to motivation and achievement in middle school. Motivation and Emotion, 34(4), 371383. https://doi.org/https://doi.org/10.1007/ s11031-010-9181-x

Iyengar, S. S., \& Lepper, M. R. (1999). Rethinking the value of choice: a cultural perspective on intrinsic motivation. Journal of Personality and Social Psychology, 76(3), 349-366. https://doi.org/ttp://dx.doi. org/10.1037/0022-3514.76.3.349

Kanat-Maymon, Y., Roth, G., Assor, A., \& Raizer, A. (2016). Controlled by Love: The Harmful Relational Consequences of Perceived Conditional Positive Regard. Journal of Personality, 84(4), 446460. https://doi.org/10.1111/jopy.12171
Karagiannidis, Y., Barkoukis, V., Gourgoulis, V., Kosta, G., \& Antoniou, P. (2015). The role of motivation and metacognition on the development of cognitive and affective responses in physical education lessons: A self-determination approach. Motricidade, 11(1), 135-150. https://doi.org/http:// dx.doi.org/10.6063/motricidade.3661

Knee, C. R., Lonsbary, C., Canevello, A., \& Patrick, H. (2005). Self-determination and conflict in romantic relationships. Journal of Personality and Social Psychology, 89(6), 997-1009. https://doi.org/https://doi. org/10.1037/0022-3514.89.6.997

Lamborn, S. D., \& Groh, K. (2009). A four-part model of autonomy during emerging adulthood: Associations with adjustment. International Journal of Behavioral Development, 33(5), 393-401. https:/ / doi. org/https://doi.org/10.1177/0165025409338440

Lee, J., Yu, H., \& Choi, S. (2012). The influences of parental acceptance and parental control on school adjustment and academic achievement for South Korean children: the mediation role of self-regulation. Asia Pacific Education Review, 13(2), 227-237. https://doi.org/https://doi. org/10.1007/s12564-011-9186-5

Meurer, S. T., Benedetti, T. R. B., \& Mazo, G. Z. (2012). Fatores motivacionais de idosos praticantes de exercícios físicos: um estudo baseado na teoria da autodeterminação. Estudos de Psicologia (Natal), 17(2), 299-304. https://doi.org/https://doi. org/10.1590/S1413-294X2012000200014

Milyavskaya, M., \& Koestner, R. (2011). Psychological needs, motivation, and well-being: A test of selfdetermination theory across multiple domains. Personality and Individual Differences, 50, 387-391. https://doi.org/https://doi.org/10.1016/j. paid.2010.10.029

Moutão, J., Alves, S. M., Monteiro, D., \& Cid, L. (2015). O papel de mediação das necessidades psicológicas na associação entre o suporte de autonomia e o bem-estar psicológico em praticantes de fitness. Motricidade, 11(2), 29-40. https://doi.org/http:// dx.doi.org/10.6063/motricidade.3734

Ng, F. F. Y., Kenney-Benson, G. A., \& Pomerantz, E. M. (2004).Children's achievementmoderates the effects of mother's use of control and autonomy support. American Psychologist, 75(3), 764-780. https:// doi.org/10.1111/j.1467-8624.2004.00705.x

Psico-USF, Bragança Paulista, v. 24, n. 2, p. 383-392, abr./jun. 2019 
Nishimura, T., \& Takashi, S. (2016). Basic psychological need satisfaction and frustration in japan: controlling for the big five personality traits. Japanese Psychological Research, 58(4), 320-331. https://doi. org/https://doi.org/10.1111/jpr.12131

Pavlidis, K., \& McCauley, E. (2001). Autonomy and relatedness in family interactions with depressed adolescents. Journal of Abnormal Child Psychology, 29(1), 11-21. https://doi.org/http://dx.doi. org/10.1023/A:1005295328151

Roth, G., Assor, A., Kanat-Maymon, Y., \& Kaplan, H. (2007). Autonomous motivation for teaching: How self-determined teaching may lead to self-determined learning. Journal of Educational Psychology, 99(4), 761-774. https://doi.org/https:// doi.org/10.1037/0022-0663.99.4.761

Ryan, R. M. (1995). Psychological needs and the facilitation of integrative processes. Journal of Personality, 63(3), 397-427. https://doi.org/https:// doi.org/10.1111/j.1467-6494.1995.tb00501.x

Ryan, R. M., \& Connell, J. P. (1989). Perceived locus of causality and internalization: examining reasons for acting in two domains. Journal of Personality and Social Psychology, 57(5), 749-761. https://doi.org/ http://dx.doi.org/10.1037/0022-3514.57.5.749

Ryan, R. M., \& Deci, E. L. (2000a). Intrinsic and Extrinsic Motivations: Classic Definitions and New Directions. Contemporary Educational Psychology, 25, 54-67. https://doi.org/doi:10.1006/ ceps. 1999.1020

Ryan, R. M., \& Deci, E. L. (2000b). Self-determination theory and the facilitation of intrinsic motivation, social development, and well-being. The American Psychologist, 55(1), 68-78. https://doi.org/https:// doi.org/10.1037/0003-066X.55.1.68

Ryan, R. M., \& Deci, E. L. (2002). Overview of selfdetermination theory: an organismic dialectical perspective. In Handbook of self-determination research (p. 3-33). Rochester: The University of Rochester Press.

Ryan, R. M., \& Deci, E. L. (2006). Self-Regulation and the Problem of Human
Autonomy: Does Psychology Need Choice, SelfDetermination, and Will? Journal of Personality, 74(6), 1557-1586. https://doi.org/https://doi. org/10.1111/j.1467-6494.2006.00420.x

Ryan, R. M., \& Deci, E. L. (2017). Self-determination theory: Basic psychological needs in motivation, development, and wellness. New York, NY, US: Guilford Press.

Ryan, R. M., Deci, E. L., Grolnick, W. S., \& La Guardia, J. G. (2006). The significance of autonomy and autonomy support in psychological development and psychopathology. In Developmental psychopatology: theory and method (p. 795-849). Hoboken, NJ, USA: Wiley.

Ryan, R. M., \& Frederick, C. (1997). On energy, personality, and health: subjective vitality as a dynamic reflection of well-being. Journal of Personality, 65(3), 529-565. https://doi.org/https://doi. org/10.1111/j.1467-6494.1997.tb00326.x

Ryan, R. M., Kuhl, J., \& Deci, E. L. (1997). Nature and autonomy: an organizational view of social and neurobiological aspects of self-regulation in behavior and development. Development and Psychopathology, 9(4), 701-728. https://doi.org/http:// dx.doi.org/10.1017/S0954579497001405

Van Petegem, S., Beyers, W., Vansteenkiste, M., \& Soenens, B. (2012). On the association between adolescent autonomy and psychosocial functioning: Examining decisional independence from a selfdetermination theory perspective. Developmental Psychology, 48(1), 76-88. https://doi.org/https:// doi.org/10.1037/a0025307

Wong, M. M. (2008). Perceptions of parental involvement and autonomy support: Their relations with self-regulation, academic performance, substance use and resilience among adolescents. North American Journal of Psychology, 10(3), 497-518. https:// doi.org/https://selfdeterminationtheory.org/ SDT/documents/2008_Wong_NAJOP.pdf

Recebido em: 23/01/2018 Reformulado em: 09/08/2018; 12/09/2018

Aprovado em: 28/09/2018 
Sobre os autores:

Daniela Bergesch D’Incao Marrone é psicóloga, mestre em Psicologia do Desenvolvimento pela Universidade Federal do Rio Grande do Sul (2015) e, atualmente, doutoranda na Universidade Federal do Rio Grande do Sul. Além disso, possui pós-graduação em psicologia clínica individual de crianças, adolescentes, adultos, casal e família.

ORCID: https://orcid.org/0000-0002-1820-2861

Email: dbdincao@gmail.com

Claudio Simon Hutz é professor titular da Universidade Federal do Rio Grande do Sul e coordenador do Laboratório de Mensuração do PPG Psicologia da UFRGS, foi, ainda, presidente da Associação Nacional de Pesquisa e Pós-Graduação em Psicologia (ANPEPP), do Instituto Brasileiro de Avaliação Psicológica (IBAP) e da Associação Brasileira de Psicologia Positiva (ABP+).

ORCID: https://orcid.org/0000-0002-3252-7339

Email: claudio.hutz@gmail.com

Contato com os autores:

Rua Ramiro Barcellos, 2600, sala 101, Santa Cecília

Porto Alegre-RS, Brazil

CEP: 90035-003 